\title{
Synaptic Interactions between Thalamic Inputs to Simple Cells in Cat Visual Cortex
}

\author{
W. Martin Usrey, ${ }^{1,2}$ Jose-Manuel Alonso, ${ }^{1,3}$ and R. Clay Reid ${ }^{1,2}$ \\ 1Laboratory of Neurobiology, The Rockefeller University, New York, New York 10021, 2Department of Neurobiology, \\ Harvard Medical School, Boston, Massachusetts 02115, and '3Department of Psychology, University of Connecticut, Storrs \\ Mansfield, Connecticut 06269
}

\begin{abstract}
We performed experiments in the cat geniculocortical pathway, in vivo, to examine how presynaptic spikes interact to influence the firing of postsynaptic targets. In particular, we asked (1) how do multiple spikes from a single presynaptic neuron interact to influence the firing of a postsynaptic target (homosynaptic interactions), (2) how do spikes from two different presynaptic neurons interact (heterosynaptic interactions), and (3) what is the time course of homosynaptic and heterosynaptic interactions? We found that both homosynaptic and heterosynaptic interactions increase the likelihood of driving a postsynaptic spike,
\end{abstract}

although with different time courses. For two spikes traveling down a single geniculate axon, the second spike is more effective than the first for $\sim 15 \mathrm{msec}$. For two spikes on separate axons, the interaction is faster $(\sim 7 \mathrm{msec}$ duration, $\sim 2.5 \mathrm{msec}$ time constant). Thus changes in firing rate are perhaps best relayed by homosynaptic interactions, whereas heterosynaptic interactions may help detect coincident spikes from different thalamic inputs.

Key words: lateral geniculate nucleus; thalamus; Area 17; geniculocortical; coincidence detection
From intracellular studies, in vitro, much is known about how the timing of presynaptic impulses can facilitate and/or depress the EPSPS evoked in the postsynaptic cell (Magleby, 1987; Zucker, 1989). Little is known, however, about the role of presynaptic timing at the level of the postsynaptic cell's spike train during sensory processing. In the visual pathway of the cat, simple cells in layer 4 of visual cortex receive convergent input from multiple geniculate cells (Hubel and Wiesel, 1962; Tanaka, 1983; 1985; Reid and Alonso, 1995). This raises the question of how geniculate action potentials interact to drive simple-cell responses. Two broad categories of potential interaction include (1) heterosynaptic interactions - interactions between action potentials traveling down different geniculate axons, and (2) homosynaptic interactions-interactions between action potentials traveling down single geniculate axons.

Several lines of evidence indicate that geniculate impulses must interact at some level to drive simple-cell responses. First, the transfer of presynaptic spikes to postsynaptic spikes is not one to one. Approximately 30 geniculate cells provide synaptic input to an individual simple cell (for review, see Reid et al., 2000), and each of these geniculate cells is considerably more active than their simple-cell target (Reid and Alonso, 1995; Alonso, et al., 1996). Second, there is a dramatic transformation in receptive-field structure between geniculate cells and their target simple cells. Geniculate cells have receptive fields with circular centers ('on' or 'off') and antagonistic surrounds (Hubel and Wiesel, 1961). In contrast, simple cells have elongated receptive fields with adjacent on and off subregions (Hubel and Wiesel, 1962). Several studies have shown that the elongated, on and off subregions of the simple cell result from convergent input from multiple geniculate cells that have overlapping receptive fields of matching sign (Hubel and Wiesel,

Received Jan. 31, 2000; revised April 19, 2000; accepted April 20, 2000.

This work was supported by National Institutes of Health Grants EY06604 EY10115, EY05253, and EY12196, the Klingenstein Fund, the Fulbright/MEC, the Charles H. Revson Foundation, and the Harvard Mahoney Neuroscience Institute. Expert technical assistance was provided by Kathleen McGowan, Christine Gallagher, and David Landsberger.

Correspondence should be addressed to R. Clay Reid, Department of Neurobiology, Harvard Medical School, 220 Longwood Avenue, Boston, MA 02115. E-mail: clay_reid@hms.harvard.edu.

Dr. Usrey's current address: Center for Neuroscience, University of California, Davis, Davis, CA 95616.

Copyright (C) 2000 Society for Neuroscience $0270-6474 / 00 / 205461-07 \$ 15.00 / 0$
1962; Tanaka, 1983, 1985; Reid and Alonso, 1995; Alonso et al., 1996). Third, previous work from our laboratory has shown that when two presynaptic geniculate cells fire spikes within $1 \mathrm{msec}$ of each other, the spikes interact synergistically to drive simple-cell responses (Alonso et al., 1996). Although this study demonstrated that presynaptic spikes from two geniculate cells reinforce each other (heterosynaptic interactions), the study did not examine the time course of the interaction. Furthermore, it is an open question as to how pairs of spikes from a single geniculate cell interact (homosynaptic interactions) to drive simple-cell spikes.

To study the interactions between homosynaptic and heterosynaptic inputs to cortical simple cells, we simultaneously recorded the responses of monosynaptically connected geniculate cells and simple cells in the cat in vivo and examined the interactions between pairs of presynaptic spikes. This approach is similar in style to a recent study from our laboratory that examined homosynaptic interactions between pairs of spikes from retinal ganglion cells to geniculate cells [Usrey et al. (1998); also see Mastronarde (1987)]. For the pathway from retina to LGN, we found that homosynaptic interactions between pairs of spikes are reinforcing for $\sim 30 \mathrm{msec}$. In the current study, we show that homosynaptic and heterosynaptic interactions at the next stage of processing, between geniculate inputs to the cortex, are likewise reinforcing, although with shorter time scales.

\section{MATERIALS AND METHODS}

Fourteen adult cats were used in this study. All surgical and experimental procedures conformed to National Institutes of Health and U.S. Department of Agriculture guidelines. These procedures have been reported previously (Alonso et al., 1996; Usrey et al., 1998, 1999). Surgical anesthesia was induced with ketamine $(10 \mathrm{mg} / \mathrm{kg}$, i.m. $)$, followed by thiopental sodium $(20 \mathrm{mg} / \mathrm{kg}$, i.v., supplemented as needed). Once all surgical procedures were complete, anesthesia was maintained with thiopental sodium $\left(2 \mathrm{mg} \cdot \mathrm{kg}^{-1} \cdot \mathrm{h}^{-1}\right.$, i.v., supplemented as needed $)$. Animals were then paralyzed with vecuronium bromide $\left(0.2 \mathrm{mg} \cdot \mathrm{kg}^{-1} \cdot \mathrm{h}^{-1}\right.$, i.v. $)$ and ventilated mechanically. Proper depth of anesthesia was ensured throughout the experiment by (1) monitoring the EEG for changes in slow-wave/spindle activity and (2) monitoring the EKG and expired $\mathrm{CO}_{2}$ for changes associated with a decrease in the depth of anesthesia.

Receptive fields of geniculate cells were mapped quantitatively by reverse correlation (Citron et al., 1981; Jones and Palmer, 1987) using pseudorandom spatiotemporal white-noise stimuli (m-sequences) (Sutter, 1992; Reid et al., 1997). The stimulus was a $16 \times 16$ grid of rapidly changing black and white squares (pixels). The stimuli were created with an AT-Vista graphics card (Truevision, Indianapolis, IN) running at a 

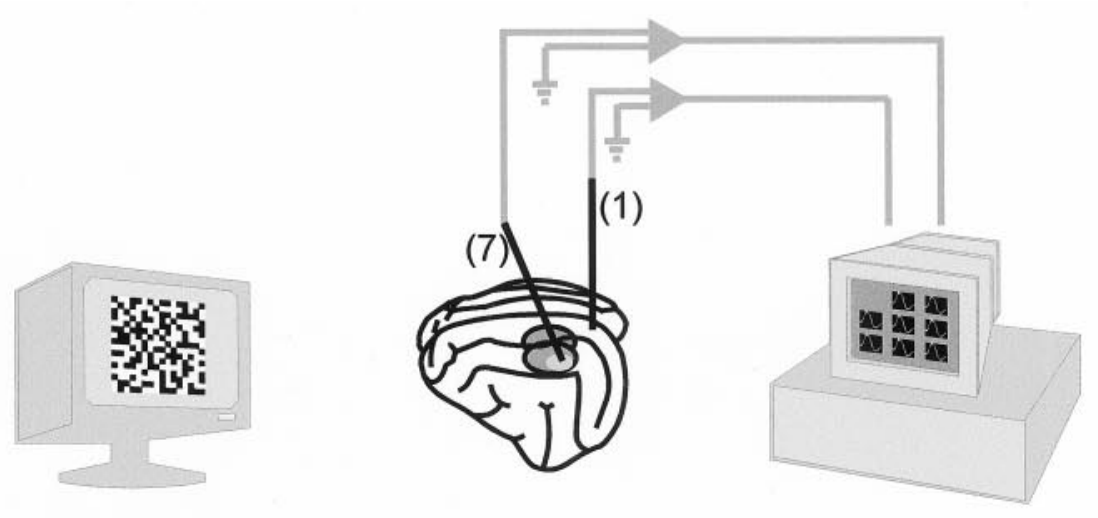
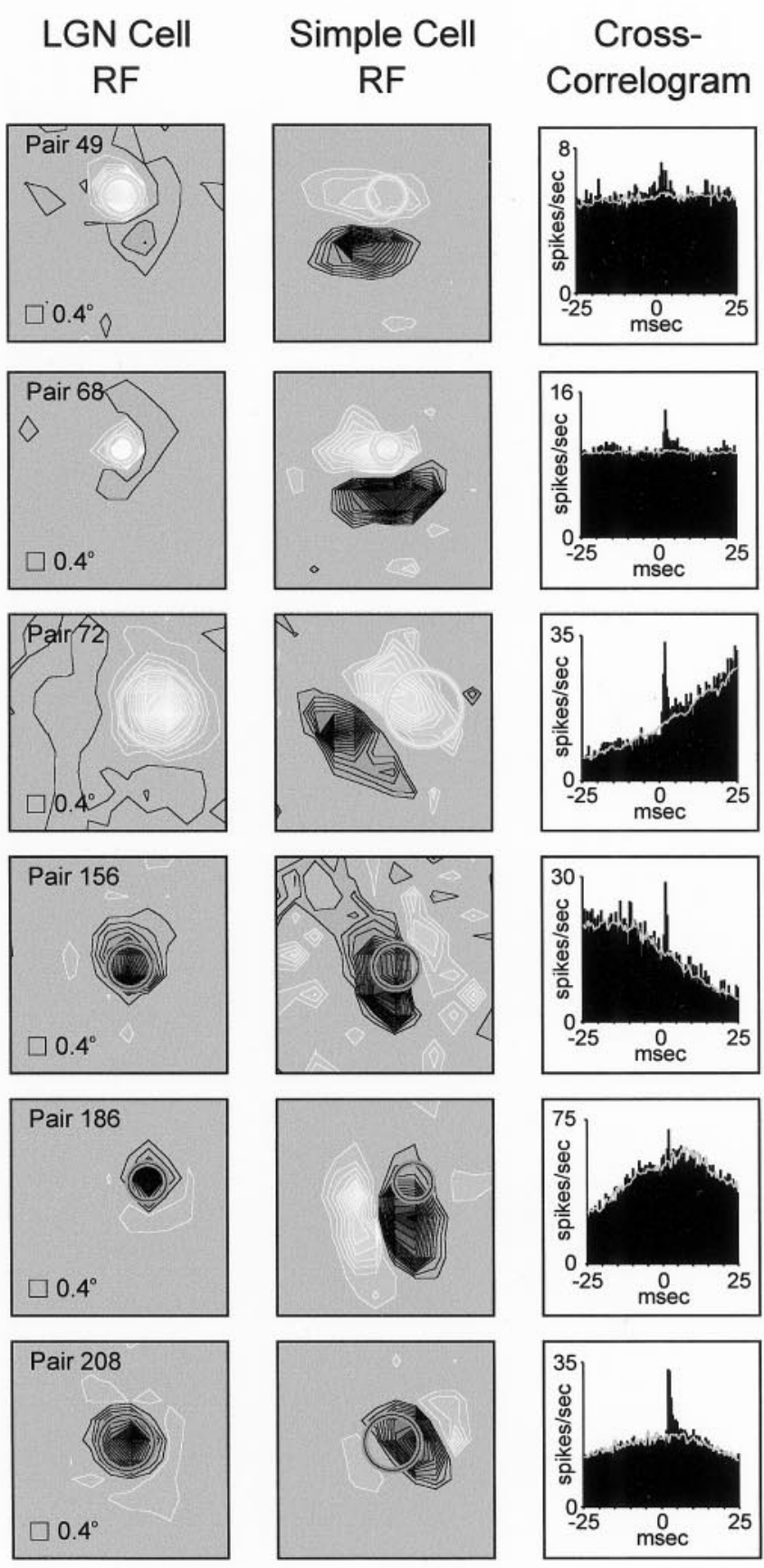
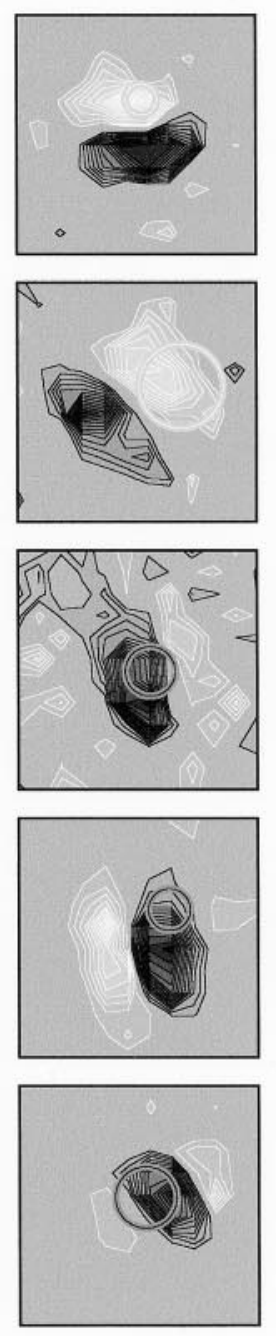
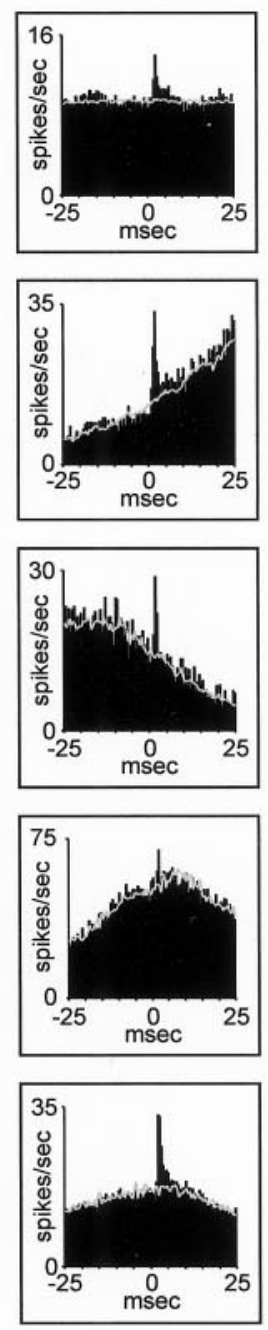

Simple Cell RF
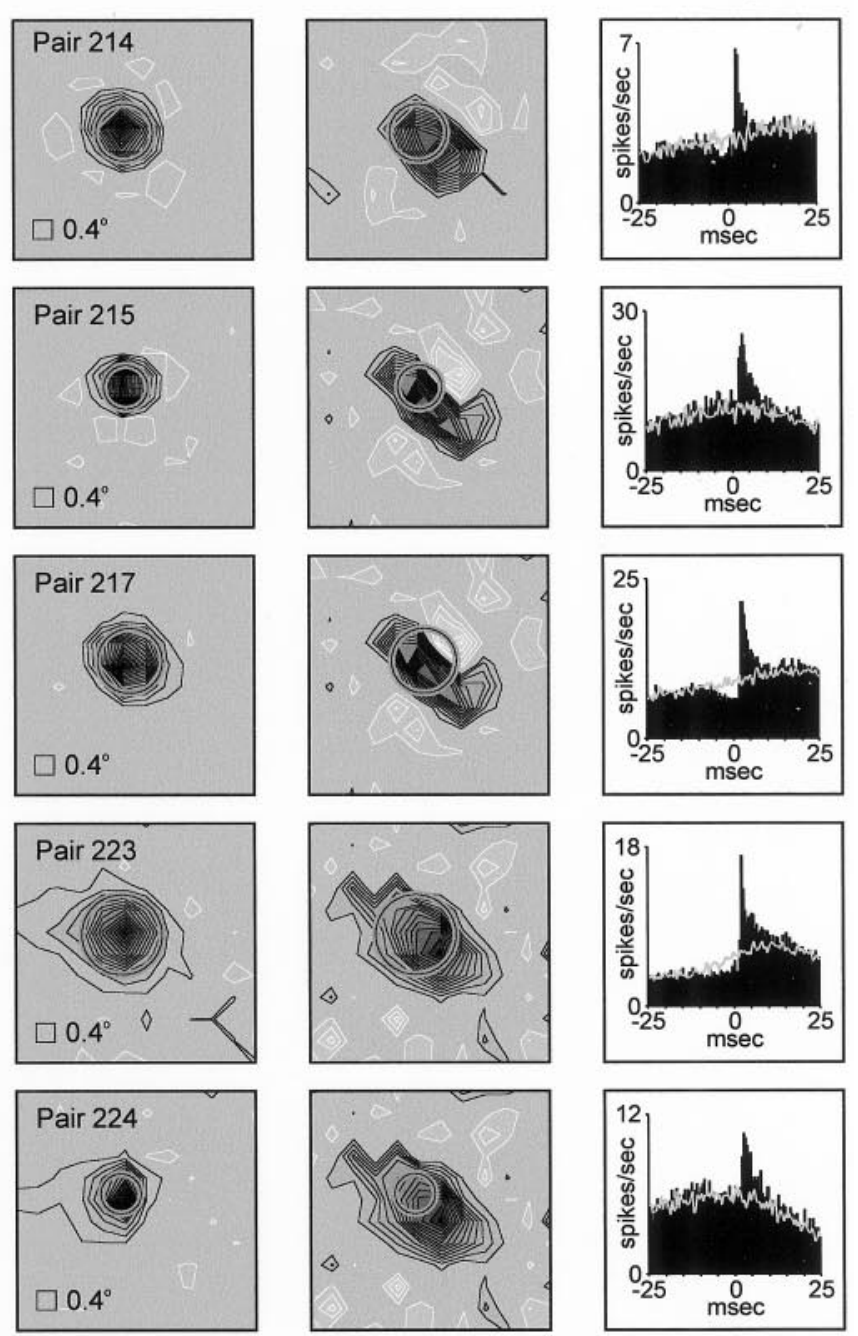

CrossCorrelogram
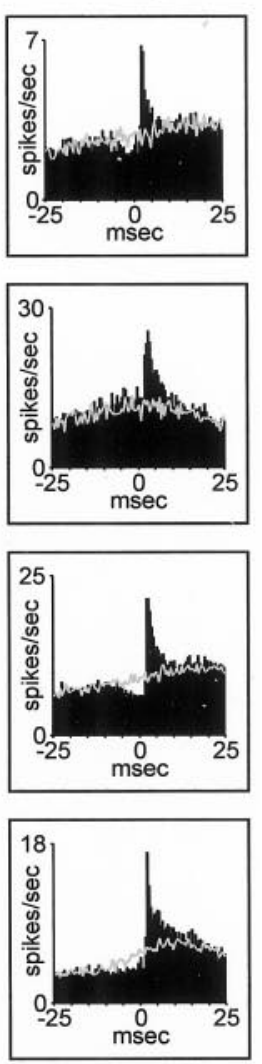
frame rate of $128 \mathrm{~Hz}$. The stimulus program was developed with subroutines from a runtime library, YARL, written by Karl Gegenfurtner (New York University). The mean luminance of the stimulus monitor was 40-50 $\mathrm{cd} / \mathrm{m}^{2}$. Pixels were small enough to map receptive fields with a reasonable amount of detail $(\sim 0.4 \%$ pixel $)$. Once receptive fields were mapped with the white-noise stimulus, large numbers of spikes were collected for crosscorrelation analysis using an optimally oriented, drifting (4 Hz) sine-wave grating.

Simultaneous recordings were made from geniculate and cortical neurons that had overlapping receptive fields. Geniculate recordings were made with the Eckhorn multi-electrode array (Eckhorn and Thomas, 1993). Cortical recordings were made with individual tungsten electrodes (Hubel, 1957). Spike isolation was confirmed with off-line waveform analysis (Datawave Systems, Longmont, CO), presence of a refractory period as seen in autocorrelations, and observation of analog data recorded on tape. Significance of correlogram peaks was assessed with the method of Reid and Alonso (1995) using a bandpass filter of $75-750 \mathrm{~Hz}$ to capture the fast peaks but exclude the slower stimulus dependent correlations. The peak integral was determined from unfiltered correlograms $(3.0 \mathrm{msec}$ range around maximum), minus the shuffle correlation and/or baseline (taken from $3 \mathrm{msec}$ ranges immediately before and after the peak range). The efficacy of geniculate spikes was defined as (peak integral)/(total geniculate spikes). For the analysis of homosynaptic and heterosynaptic interactions between pairs of spikes, the efficacy of each spike in a pair was performed in the same manner. The definition of these pairs of spikes is described in legends to Figures 3 (homosynaptic) and 5 (heterosynaptic).

\section{RESULTS}

\section{Comparing receptive fields and assessing connectivity}

Simultaneous recordings were made from 224 pairs of geniculate cells and layer 4 simple cells with overlapping receptive fields. Receptive fields were mapped using a white-noise stimulus (msequences) (Sutter, 1992; Reid et al., 1997); connectivity was assessed by cross-correlating geniculate and simple-cell spike trains (see Materials and Methods). The distinguishing feature in a cross-correlogram indicative of a monosynaptic connection is a rapidly rising, short-latency (2-4 msec) peak (Tanaka, 1983, 1985; Reid and Alonso, 1995; Reid, 2000). Of the 224 pairs of cells, 61 were determined to be monosynaptically connected. Consistent with previous reports (Tanaka, 1983, 1985; Reid and Alonso, 1995; Alonso et al., 1996), monosynaptic connections were only seen between cells with overlapping receptive fields of the same sign (for instance, on-center geniculate receptive field overlapping the onsubregion of a simple cell).

The analysis for examining interactions between presynaptic spikes required a great deal of data. Of the 61 pairs of cells with monosynaptic connections, 11 had sufficient signal-to-noise to perform this analysis. These pairs met the criterion that the 'monosynpatic peak' in the bandpass-filtered cross-correlogram (see Materials and Methods) was at least 6 SDS above the noise. These pairs had $>10,000$ geniculate spikes $($ mean $=52,000)$ and $>2500$ cortical spikes $($ mean $=12,000)$. From this data set, we examined the interactions between pairs of geniculate spikes traveling down a single presynaptic axon (homosynaptic interactions). Receptive fields and cross-correlograms for each of these 11 pairs of cells are shown in Figure 1.

\section{Homosynaptic interactions}

To determine whether spike history influences the efficacy of geniculate spikes in driving simple-cell spikes, we looked at pairs of spikes traveling down a single geniculate axon and asked whether the first or second spike was more likely to lead to a simple-cell spike. An example illustrating the difference in first and second spike efficacy is shown in Figure 2. In this example, we recorded the responses of an off-center geniculate cell whose receptive field overlapped the off-subregion of a simultaneously recorded simple cell (Fig. 2A,B). Simple cross-correlation analysis indicated that the simple cell often fired in response to a geniculate spike (Fig. $2 C, D)$. To examine potential interactions between spikes from the geniculate cell in driving the simple cell, we extracted pairs of spikes (with $5 \mathrm{msec}$ interspike intervals) out of the original geniculate spike train and looked at the efficacy of first and second spikes (Usrey et al., 1998). These interactions are shown in two ways: as a raster plot of cortical firing with respect to paired geniculate spikes (Fig. 2E)and also as a paired-spike cross-correlogram (Fig. $2 F$ ), which is the vertical sum of the raster plot. As can be seen particularly in the paired-spike correlogram, the second spike is more likely than the first to contribute to a simple-cell response.

Geniculate cells generate action potentials with a broad range of interspike intervals. This raises the question, over what range of interspike intervals are second spikes more effective than first spikes at driving a simple-cell response? To address this question, we measured the efficacy (efficacy $=\%$ presynaptic spikes that lead to a postsynaptic spike) of first and second geniculate spikes when they occurred at interspike intervals ranging from $\sim 3 \mathrm{msec}$ to 30 msec. The shortest interspike intervals were set by the refractory period of the geniculate cell. In comparing the efficacy of two geniculate spikes, the interspike interval between them should be shorter than the interspike interval before the first spike; otherwise, the first spike will undergo similar interactions (from a previous spike) as the second spike. We therefore examined the efficacy of first and second geniculate spikes when the first spike followed a previous spike by at least 10 or $20 \mathrm{msec}$ (dead time). Note that interspike intervals greater than the dead time are difficult to interpret, because the first spike might in fact be preceded by a shorter interspike interval than the second. With interspike intervals between 4 and $10 \mathrm{msec}$, we found that second spikes were approximately twice as likely as first spikes to drive simplecell spikes (Fig. 3). At interspike intervals $>10 \mathrm{msec}$, the enhanced efficacy of second spikes diminished; at interspike intervals $>15$ msec, first and second spikes had similar efficacies.

The effect of paired-spike enhanced efficacy-second spikes are more effective than first spikes when they occur within $\sim 15 \mathrm{msec}$ of the first spike-was seen in 10 of 11 pairs of cells that we studied. The scatter plot in Figure 4 shows the relationship between the efficacy of first and second spikes for each of the cell pairs studied. The two points that fall below the line of unit slope represent values from the same pair of cells when examined with two different dead times $(>10$ and $>20 \mathrm{msec})$. All of the pairs of cells $(11 / 11)$ displayed enhanced efficacy of second spikes when the cells were excited with the white-noise stimulus (data not shown).

\section{Heterosynaptic interactions}

Out of 224 pairs of geniculate cells and simple cells in our data set, we recorded 13 'triplets' in which two geniculate cells (Fig. $5 A$, $L G N A$ and $L G N B$ ) were connected to a simultaneously recorded simple cell. Two of these cases met our strict criterion for homosynaptic analysis (described above; pairs 215/217, 223/224). These two cases, along with two additional cases (for which the stronger geniculate input was just below our criterion for the homosynaptic analysis), were examined for heterosynaptic interactions between spikes that converge onto a simple cell from different geniculate axons. Previously, we have shown that synchronous geniculate spikes $(<1 \mathrm{msec})$ from two geniculate cells reinforce each other and are synergistic in driving simple-cell responses (Alonso et al., 1996). In the present analysis, we examined the time course of this heterosynaptic reinforcement (Fig. 5A).

Figure 1. Simultaneous recordings from geniculate cells and simple cells with overlapping receptive fields. Top, Illustration of the experiment. A single electrode was inserted into layer 4 of visual cortex; up to seven electrodes were inserted into the LGN. Visual responses to a white-noise stimulus (shown) and drifting sine-wave grating were recorded. Bottom, Receptive fields and cross-correlograms for each pair of cells $(n=11)$ that were monosynaptically connected and studied for interactions between geniculate spikes. Regions of a cell's receptive field excited by the bright phase of the white-noise stimulus (see Materials and Methods) are shown in white; regions excited by the dark phase are shown in black. The two panels for each pair of receptive fields correspond to the same stimulus window. Circles represent a Gaussian fit to the geniculate receptive field (radius: $2.5 \sigma)$. Stimulus pixel size was $0.4^{\circ}$. The cross-correlograms shown to the right of the receptive fields each have a short-latency peak (above the stimulus-dependent shuffle correlogram, shown in gray), indicating a monosynaptic connection between the geniculate cell and the simple cell. 
A
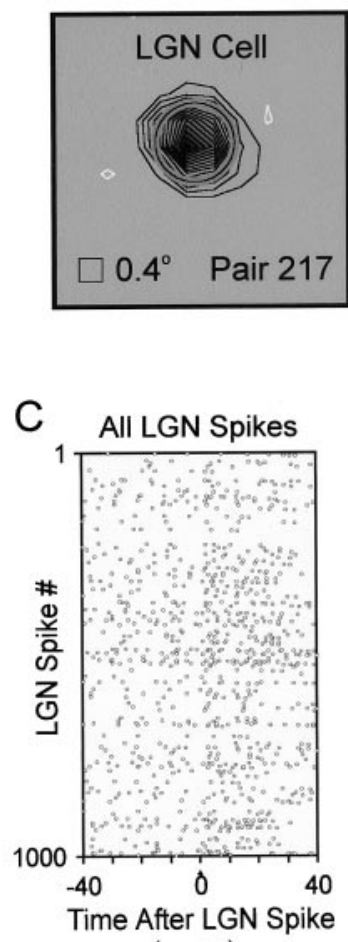

(msec)

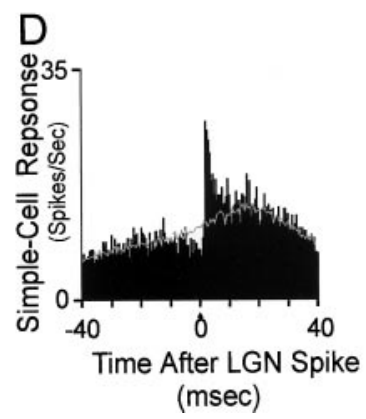

B
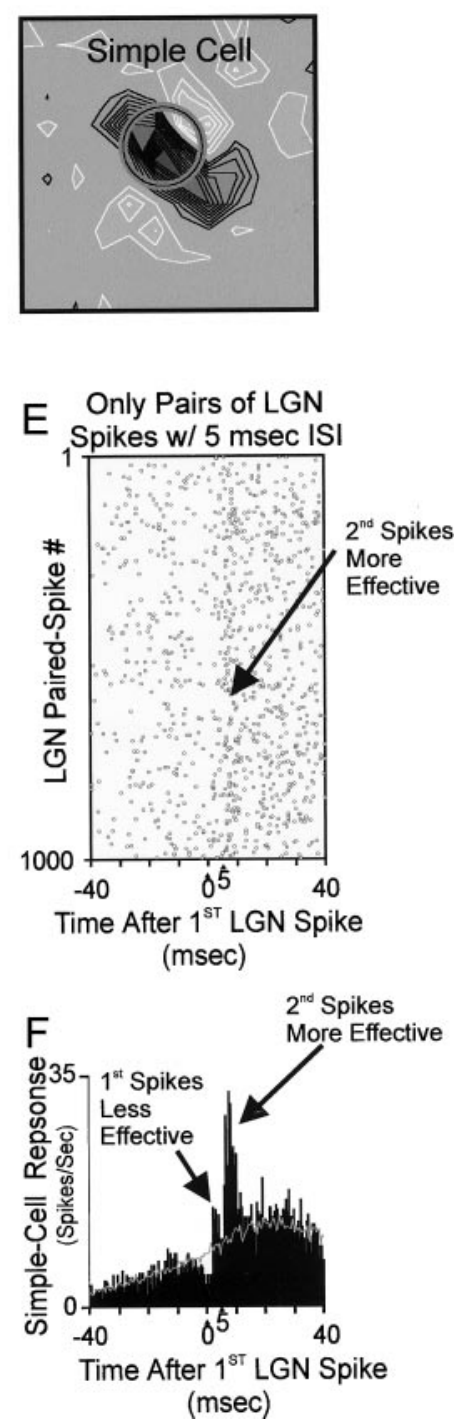

A

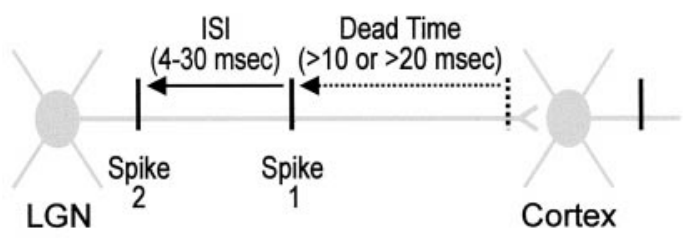

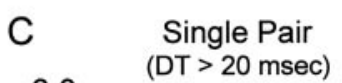
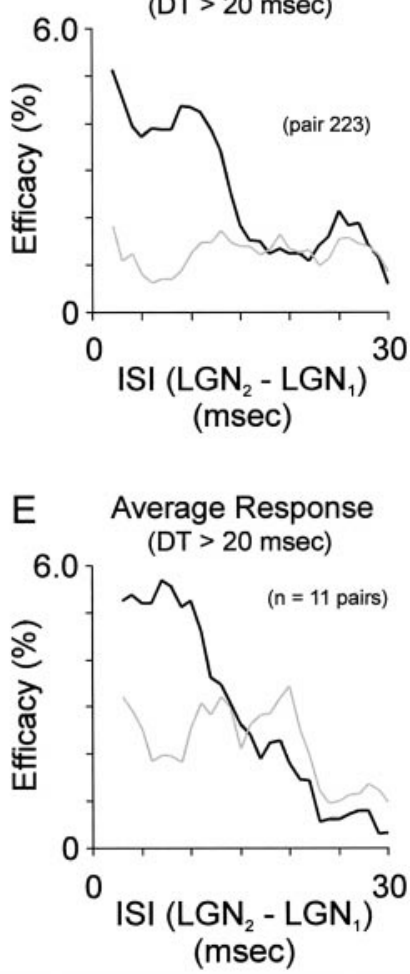
indicates that the geniculate cell provided monosynaptic input to the simple cell (Tanaka, 1983, 1985; Reid and Alonso, 1995). Visual stimulus: drifting sine-wave grating of optimal orientation. Total time: 2062 sec. Geniculate spikes: 64,779; simple-cell spikes: 8635 . Efficacy of geniculate input: $2.1 \%$ (see Materials and Methods). E, Raster plot of simple-cell firing relative to 1000 pairs of geniculate spikes, each separated by $5.0 \pm 0.5 \mathrm{msec}$ and preceded by $>5.0 \mathrm{msec}$ dead time. More simple-cell spikes followed second geniculate spikes than followed first geniculate spikes. $F$, Cross-correlogram between paired geniculate spikes and simple-cell spikes. Geniculate paired spikes: 5450 . Efficacy of first spikes (peak 1): $1.2 \%$. Efficacy of second spikes (peak 2): $5.1 \%$.

As with homosynaptic interactions, we found that a pair of spikes (as defined in Fig. 5A) from different geniculate cells reinforce each other to increase the probability that the second spike evokes a simple-cell spike. At the shortest interspike intervals studied (2 msec), cell A strongly reinforced the efficacy of cell B. In contrast to homosynaptic reinforcement, which was often constant in strength for $\sim 10 \mathrm{msec}$ and then decayed to baseline values at $\sim 15$ msec, heterosynaptic reinforcement was much briefer (Fig. $5 B, D$ ). Reinforcement decreased to $\sim 1$ /e with a time constant of $\sim 2.5$

Figure 3. Time course and magnitude of homosynaptic paired-spike enhancement. $A$, Illustration of analysis showing the temporal relationships between dead time and two successive LGN spikes. Pairs of spikes with a given interspike interval (ISI) were included in the analysis if there were no spikes before spike 1 within the dead time (10 or $20 \mathrm{msec}) . B, C$, Efficacy of pairs of geniculate spikes (percentage that evoked a simple-cell spike) that occurred at different ISIs after a dead time $>10 \mathrm{msec}$ and $>20 \mathrm{msec}$; these dead times were selected because they are shorter $(>10 \mathrm{msec})$ and longer $(>20 \mathrm{msec})$ than the duration of homosynaptic reinforcement $(\sim 15 \mathrm{msec}$; see Results for reasoning). Curves in $B$ and $C$ are from the same geniculate cell and simple cell. Gray lines: efficacy of first geniculate spikes; black lines: efficacy of second geniculate spikes. Efficacy at each geniculate ISI was calculated as in Figure 2, then smoothed with 4 msec boxcar average. $D, E$, Average efficacy profiles for all 11 pairs of cells after a dead time $>10 \mathrm{msec}$ and $>20$ msec.

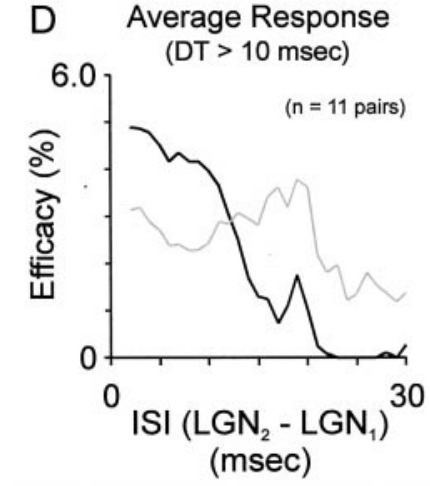
o

msec for the single example (Fig. $5 B$ ) as well as for the average (Fig. $5 C$ ). Finally, reinforcement could not be detected at intervals $>7$ msec. Because either of the two LGN cells could be 'cell A,' for each triplet we could examine the effect of the stronger geniculate input on the weaker, and vice versa. In our four examples, the heterosynaptic influence was reciprocal, but the stronger input affected the weaker more dramatically (Fig. $5 C$ ).

We wished to examine whether the fast heterosynaptic interactions were attributable to linear summation between the two geniculate inputs. That is, we asked whether the tail of the correlation between cell $\mathrm{A}$ and the cortical cell simply added with the peak of the correlation between cell B and the cortical cell. In all cases, the tail of cell A's correlation alone was much smaller than the heterosynaptic interaction between cells $\mathrm{A}$ and $\mathrm{B}$; that is, the heterosynaptic interaction between cell A and cell B was supralinear [analysis not shown; see Alonso et al. (1996)]. 


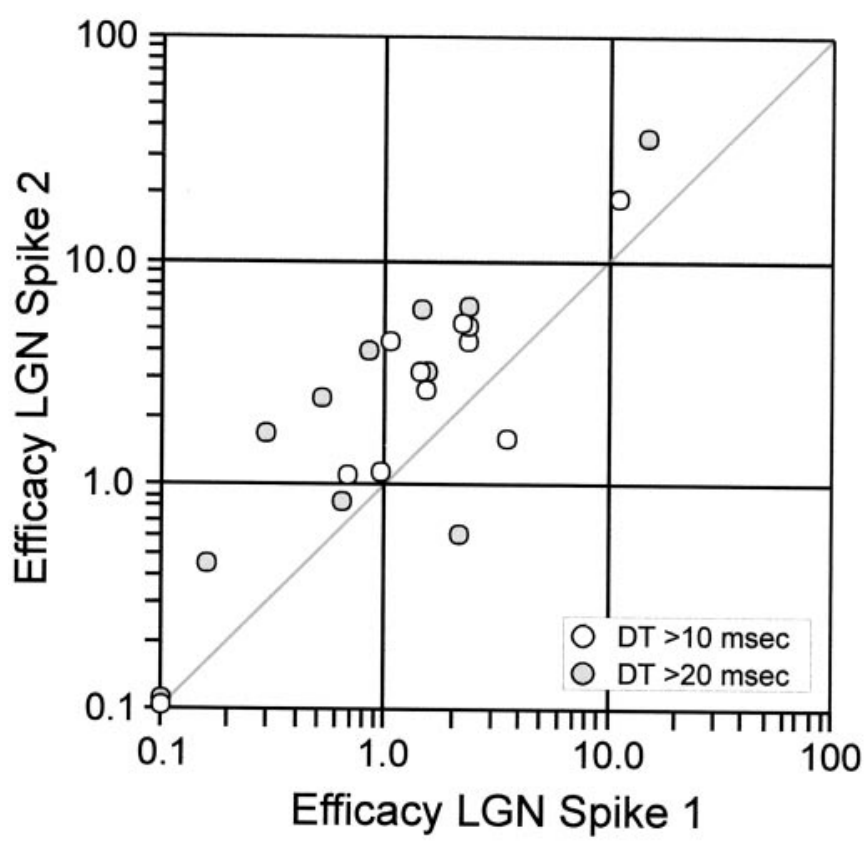

Figure 4. Scatter plot of efficacies of second versus first geniculate spikes; all but one pair of cells showed homosynaptic enhancement of second spikes. Efficacies were averaged over ISI range $4-10 \mathrm{msec}$, weighted by number of occurrences of each ISI. The visual stimulus was a drifting (4 $\mathrm{Hz}$ ) sine-wave grating. Dead time $(D T)$ was either $>10 \mathrm{msec}$ (white circles) or $>20 \mathrm{msec}$ (gray circles). Points on either axis are for efficacies $<0.1 \%$.

\section{DISCUSSION}

In our examination of homosynaptic and heterosynaptic interactions between geniculate inputs to simple cells in cat visual cortex, we found that pairs of geniculate spikes reinforce each other so that the second spike is more likely to drive simple-cell action potentials. For pairs of spikes travelling down a single geniculate axon, the window for reinforcement was $\sim 15 \mathrm{msec}$. For pairs of spikes traveling down separate geniculate axons, the window for reinforcement was shorter, $\sim 7 \mathrm{msec}$. With these heterosynaptic interactions, maximal reinforcement occurred at the shortest intervals examined and decayed with a time-constant $\sim 2.5 \mathrm{msec}$. In the following sections, we discuss the potential mechanisms of homosynaptic and heterosynaptic reinforcement and the functional implications of these two phenomena.

\section{Potential mechanisms of homosynaptic and heterosynaptic reinforcement}

For homosynaptic interactions between two spikes traveling down a single geniculate axon, reinforcement could occur by presynaptic mechanisms, postsynaptic mechanisms, or both. The most likely candidate for a presynaptic mechanism is the accumulation of calcium in the presynaptic terminal after the occurrence of a previous spike (Magleby, 1987; Zucker, 1989). Potential postsynaptic mechanisms include involvement of the membrane time constant of the postsynaptic cell (for review, see Koch et al., 1996), active dendritic conductances (Hirsch et al., 1995), and voltagegated currents that underlie action potential generation (Azouz and Gray, 2000; see also Mainen and Sejnowski, 1995; Carandini et al., 1996; Nowak et al., 1997; Volgushev et al., 1998).

A comparison of the time course of homosynaptic reinforcement with the time course of heterosynaptic reinforcement should shed some light on whether homosynaptic reinforcement occurs presynaptically or postsynaptically. Although homosynaptic inputs have potential access to both presynaptic and postsynaptic mechanisms, heterosynaptic inputs have access only to postsynaptic mechanisms. Because the time course of reinforcement was longer (approximately two times) for homosynaptic inputs compared with heterosynaptic inputs, it seems likely that at least some of the homosynaptic effect is presynaptic.
It should be noted, however, that postsynaptic mechanisms could have caused this difference in time course between heterosynaptic and homosynaptic interactions. The most likely scenario would be if inputs from two different cells tended to be farther apart than inputs from a single cell (trivially true if each afferent only provided a single synapse). In this case, however, homosynaptic inputs would, if anything, be faster than heterosynaptic. If there were passive dendritic summation and somatic spike initiation, then there would be no difference between nearby and distant inputs. If, however, there were local nonlinear mechanisms-either active conductances (Hirsch et al., 1995; Schiller et al., 1997; Sabatini and Regehr, 1999) or a shunt caused by strong synaptic input (Reid et al., 1992) - these mechanisms would speed up integration at local sites compared with distant sites. Because we find that homosynaptic interactions are, in fact, slower than heterosynaptic interactions, it seems likely that even if postsynaptic mechanisms play a role, presynaptic mechanisms must be present as well.

If there is a presynaptic component to homosynaptic reinforcement, it almost certainly involves a dynamic interplay between facilitation and depression. In the past, studies performed in vitro examining facilitation and depression usually relied on protocols in which pairs of stimuli were delivered on a relatively quiescent baseline, or trains of spikes were elicited at constant rates (Magleby, 1987; Zucker, 1989). More recently, studies in vitro (Markram and Tsodyks, 1996; Abbott et al., 1997; Dobrunz et al., 1997; Tsodyks and Markram, 1997; Varela et al., 1997; Dobrunz and Stevens, 1999; Varela et al., 1999) have begun to use more naturalistic presynaptic spike trains, similar to those measured in vivo. Under these conditions, synaptic efficacy appears to depend in a complex fashion on the local temporal structure of the input.

Although the temporal structure of the presynaptic spike train certainly is important in determining the extent of synaptic modulation, the local environment surrounding a cell, which can be quite different in vitro as compared with in vivo, also appears to play a significant role. Initial experiments performed in vitro on slices of cat visual cortex indicated that geniculate inputs undergo pairedpulse depression (Stratford et al., 1996; see also Gil et al., 1999). More recent work, however, indicates that when neuromodulators are added and the ionic environment is changed to mimic conditions present in vivo, the paired-pulse depression of inputs to visual cortical neurons can decrease and, in some cases, change to facilitation (Sanchez-Vives et al., 1999).

The time course of homosynaptic reinforcement that we recorded in vivo $(\sim 15 \mathrm{msec})$ was relatively short compared with the time course of paired-pulse facilitation that has been measured in other brain regions in vitro (Magleby, 1987; Zucker, 1989). In a recent study, we examined homosynaptic interactions between spikes from retinal ganglion cells to geniculate cells in the cat (Usrey et al., 1998). Results from this study showed that retinal spikes also undergo strong, paired-spike reinforcement for interspike intervals up to $\sim 30 \mathrm{msec}$. Although the retinogeniculate window for reinforcement is somewhat longer than that measured in the current study of geniculocortical inputs, both windows are still relatively short compared with results obtained in vitro. This finding is consistent with other observations that many cellular properties/reactions become faster when they occur in the in vivo environment (Sabatini and Regehr, 1996, 1999).

\section{Functional implications of homosynaptic and heterosynaptic reinforcement}

A comparison between the time courses of homosynaptic versus heterosynaptic interactions demonstrates that not all geniculate spikes are equal. For a pair of spikes traveling down a single geniculate axon, the second spike is more effective than the first at driving a target simple cell for $\sim 15 \mathrm{msec}$. For two spikes traveling down separate geniculate axons, spikes interact for a shorter period of time; reinforcement is strongest at the shortest interspike intervals and drops rapidly to undetectable levels by $\sim 7 \mathrm{msec}$. Furthermore, we have shown that when these geniculate spikes arrive 
A

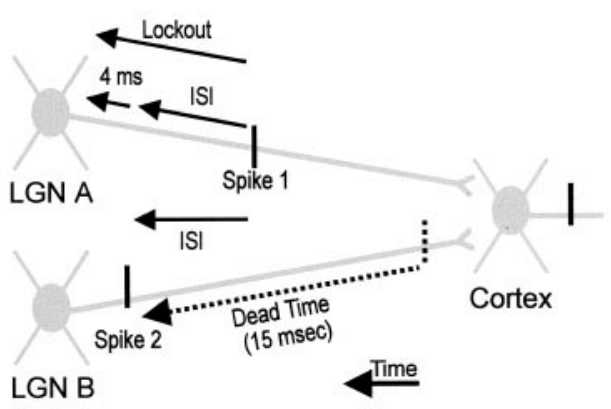

Figure 5. Time course and magnitude of heterosynaptic paired-spike enhancement. A, Illustration of analysis showing the temporal relationships between spikes from two LGN cells (LGN $A$ and $B$ ). Spike 1 was from cell $A$; spike 2 was from cell $B$. For various ISIs between spike 1 and spike 2, it was required that cell A fire no spikes during a lockout period, which included the ISI plus $4 \mathrm{msec}$. The additional $4 \mathrm{msec}$ insured that a second spike from cell A did not sum with spike 2 (from cell $\mathrm{B}$ ). In addition, the analysis required that cell $\mathrm{B}$ produced no spikes during a dead time of $15 \mathrm{msec}$ (the approximate duration of homosynaptic interactions) before spike 2. $B$, Time course of heterosynaptic interactions (effect of cell A on cell $\mathrm{B})$ versus homosynaptic interactions (effect of $\mathrm{B}$ on B) for a single cell. $C$, Averaged heterosynaptic interactions for the 4 'triplets' in our data set. For each triplet, the effect was more pronounced when the strong input preceded the weak input. $D$ Comparison of average heterosynaptic interactions (strong input preceding weak) versus average homosynaptic interactions for same cells (as in $B$ ).

\section{Second-Spike Efficacy} (Heterosynaptic, Strong Input before Weak vs. Weak before Strong)

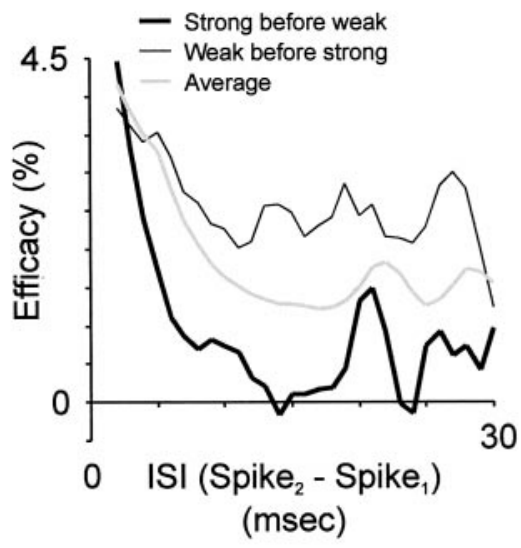

\section{B Second-Spike Efficacy Hetero- vs. Homosynaptic (Single Case)}

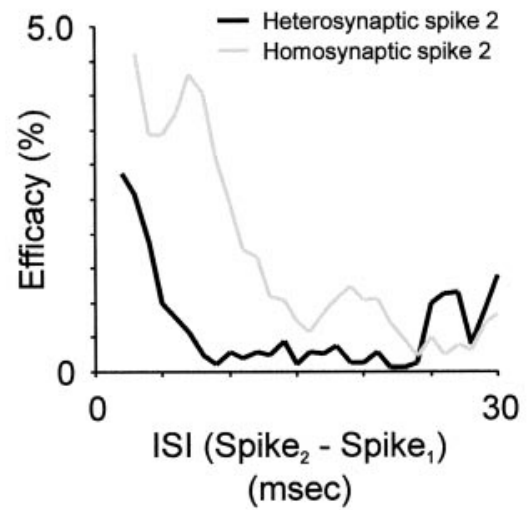

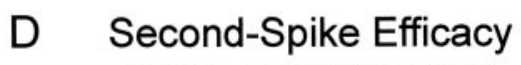

Hetero- vs. Homosynaptic (Average)

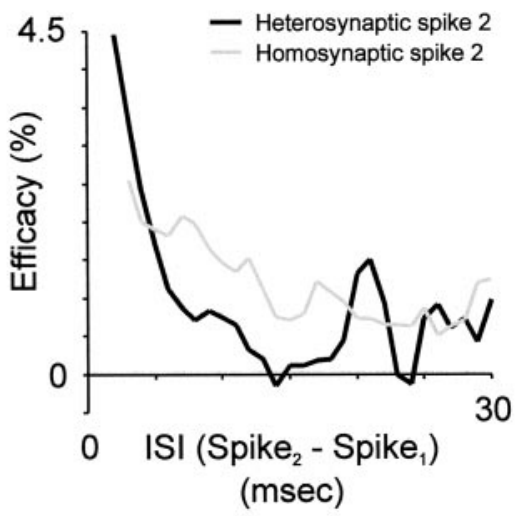

within $1 \mathrm{msec}$ of each other, they interact synergistically to drive simple-cell responses (Alonso et al., 1996). These results suggest that information encoded in firing rate (or bursts) (Sherman, 1996; Reinagel et al., 1999; Martinez-Conde et al., 2000) is best detected by homosynaptic interactions, whereas information encoded in coincident firing (Sillito et al., 1994; Konig et al., 1996; Dan et al., 1998 ) is best detected by heterosynaptic interactions.

Recently, we have also shown that geniculate cells that receive common input from a retinal ganglion cell fire up to $40 \%$ of their spikes within $1 \mathrm{msec}$ of each other (Cleland, 1986; Sillito, et al., 1994; Alonso et al., 1996; Castelo-Branco, et al., 1996; Usrey et al., 1998). These synchronous spikes in the LGN are preferentially driven by retinal spikes during periods of high retinal firing (Usrey et al., 1998). Therefore, it is possible that the primary benefit of such a mechanism would be to selectively amplify signals from retinal ganglion cells that are being driven very strongly (as distinct from any mechanism that might alter the receptive-field properties of cortical neurons) (Sillito et al., 1994). Furthermore, additional information could be potentially encoded if these highly synchronous spikes could be detected independently (Dan et al., 1998). Although coincidence detection has been the subject of much debate and may not occur at all cortical synapses (for review, see König et al., 1996; Usrey and Reid, 1999), it may be important in the pathway from LGN to cortex, where there is (1) a mechanism for generating coincident geniculate spikes, (2) additional informa- tion embedded in coincident spikes, and (3) a mechanism for reading off coincident spikes.

\section{REFERENCES}

Abbott LF, Varela JA, Sen K, Nelson SB (1997) Synaptic depression and cortical gain control. Science 275:220-224.

Alonso JM, Usrey WM, Reid RC (1996) Precisely correlated firing in cells of the lateral geniculate nucleus. Nature 383:815-819.

Azouz R, Gray CM (2000) Dynamic spike threshold reveals synaptic coincidence detection in cortical cells in vivo. Proc Natl Acad Sci USA, in press.

Carandini M, Mechler F, Leonard CS, Movshon JA (1996) Spike train encoding by regular-spiking cells of the visual cortex. J Neurophysiol 76:3425-3441

Castelo-Branco M, Neuenschwander S, Herculano S, Singer W (1996) Synchronization of visual responses between the cortex, LGN and retina in the anesthetized cat. Soc Neurosci Abstr 22:643.

Citron MC, Emerson RC, Ide LS (1981) Spatial and temporal receptivefield analysis of the cat's geniculocortical pathway. Vision Res 21:385-396.

Cleland BG (1986) The dorsal lateral geniculate nucleus of the cat. In: Visual neuroscience (Pettigrew JD, Sanderson KS, Levick WR, eds), pp 111-120. London: Cambridge UP.

Dan Y, Alonso JM, Usrey WM, Reid RC (1998) Coding of visual information by precisely correlated spikes in the lateral geniculate nucleus. Nat Neurosci 1:501-507.

Dobrunz LE, Stevens CF (1999) Response of hippocampal synapses to natural stimulation patterns. Neuron 22:157-166.

Dobrunz LE, Huang EP, Stevens CF (1997) Very short-term plasticity in hippocampal synapses. Proc Natl Acad Sci USA 94:14843-14847.

Eckhorn R, Thomas U (1993) A new method for the insertion of multiple microprobes into neural and muscular tissue, including fiber electrodes, fine wires, needles and microsensors. J Neurosci Methods 49:175-179. 
Gil Z, Connors BW, Amitai Y (1999) Efficacy of thalamocortical and intracortical synaptic connections: quanta, innervation, and reliability. Neuron 23:385-397.

Hirsch JA, Alonso JM, Reid RC (1995) Visually evoked calcium action potentials in cat striate cortex. Nature 378:612-616.

Hubel DH (1957) Tungsten microelectrode for recording from single units. Science 125:549-550.

Hubel DH, Wiesel TN (1961) Integrative action in the cat's lateral geniculate body. J Physiol (Lond) 155:385-398.

Hubel DH, Wiesel TN (1962) Receptive fields, binocular interaction and functional architecture in the cat's visual cortex. J Physiol (Lond) 160: $106-154$.

Jones JP, Palmer LA (1987) The two-dimensional spatial structure of simple receptive fields in cat striate cortex. J Neurophysiol 58:1187-1211.

Koch C, Rapp M, Segev I (1996) A brief history of time (constants). Cereb Cortex 6:93-101.

König P, Engel AK, Singer W (1996) Integrator or coincidence detector? The role of the cortical neuron revisited. Trends Neurosci 19:130-137.

Magleby KL (1987) Short-term changes in synaptic efficacy. In: Synaptic function (Edelman GM, Gall WE, Cowan WM, eds), pp 21-56. New York: Wiley.

Mainen ZF, Sejnowski TJ (1995) Reliability of spike timing in neocortical neurons. Science 268:1503-1506.

Markram H, Tsodyks M (1996) Redistribution of synaptic efficacy between neocortical pyramidal neurons. Nature 382:807-810.

Martinez-Conde S, Macknik SL, Hubel DH (2000) Microsaccadic eye movements and firing of single cells in the striate cortex of macaque monkeys. Nat Neurosci 3:251-258.

Mastronarde DN (1987) Two classes of single-input X-cells in cat lateral geniculate nucleus. II. Retinal inputs and the generation of receptivefield properties. J Neurophysiol 57:381-413.

Nowak LG, Sanchez-Vives MV, McCormick DA (1997) Influence of low and high frequency inputs on spike timing in visual cortical neurons. Cereb Cortex 7:487-501.

Perkel DH, Gerstein GL, Moore GP (1967) Neuronal spike trains and stochastic point processes. II. Simultaneous spike trains. Biophys J 7:419-440.

Reid RC (2000) Divergence and reconvergence: multielectrode analysis of feedforward connections in the visual system (Nicolelis MAL, ed). New York: Springer Verlag, in press.

Reid RC, Alonso JM (1995) Specificity of monosynaptic connections from thalamus to visual cortex. Nature 378:281-284.

Reid RC, Victor JD, Shapley RM (1992) Broadband temporal stimuli decrease the integration time of neurons in cat striate cortex. Vis Neurosci 9: $39-45$.

Reid RC, Victor JD, Shapley RM (1997) The use of m-sequences in the analysis of visual neurons: linear receptive field properties. Vis Neurosci 14:1015-1027.

Reid RC, Alonso JM, Usrey WM (2000) Integration of thalamic inputs to cat primary visual cortex. In: Cerebral cortex (13): cat visual cortex. (Payne BR, Peters A, eds). New York: Plenum, in press.

Reinagel P, Godwin D, Sherman SM, Koch C (1999) Encoding of visual information by LGN bursts. J Neurophysiol 81:2558-2569.

Sabatini BL, Regehr WG (1996) Timing of neurotransmission at fast synapses in the mammalian brain. Nature 384:170-172.

Sabatini BL, Regehr WG (1999) Timing of synaptic transmission. Annu Rev Physiol 61:521-542.

Sanchez-Vives MV, Nowak LG, McCormick DA (1999) Why might synaptic depression be lesser in vivo than in vitro? Soc Neurosci Abstr 25:2191.

Schiller J, Schiller Y, Stuart G, Sakmann B (1997) Calcium action potentials restricted to distal apical dendrites of rat neocortical pyramidal neurons. J Physiol (Lond) 505:605-616.

Sherman SM (1996) Dual response modes in lateral geniculate neurons: mechanisms and functions. Vis Neurosci 13:205-213.

Sillito AM, Jones HE, Gerstein GL, West DC (1994) Feature-linked synchronization of thalamic relay cell firing induced by feedback from the visual cortex. Nature 369:479-482.

Stratford KJ, Tarczy-Hornoch K, Martin KA, Bannister NJ, Jack JJ (1996) Excitatory synaptic inputs to spiny stellate cells in cat visual cortex. Nature 382:258-261.

Sutter EE (1992) A deterministic approach to nonlinear systems analysis. In: Nonlinear vision: determination of neural receptive fields, function and networks (Pinter R, Nabet B, eds), pp 171-220. Cleveland: CRC.

Tanaka K (1983) Cross-correlation analysis of geniculostriate neuronal relationships in cats. J Neurophysiol 49:1303-1318.

Tanaka K (1985) Organization of geniculate inputs to visual cortical cells in the cat. Vision Res 25:357-364.

Tsodyks MV, Markram H (1997) The neural code between neocortical pyramidal neurons depends on neurotransmitter release probability. Proc Natl Acad USA 94:719-723.

Usrey WM, Reid RC (1999) Synchronous activity in the visual system. Annu Rev Physiol 61:435-456.

Usrey WM, Reppas JB, Reid RC (1998) Paired-spike interactions and synaptic efficacy of retinal inputs to the thalamus. Nature 395:384-387.

Usrey WM, Reppas JB, Reid RC (1999) Specificity and strength of retinogeniculate connections. J Neurophysiol 82:3527-3540.

Varela JA, Sen K, Gibson J, Fost J, Abbott LF, Nelson SB (1997) A quantitative description of short-term plasticity at excitatory synapses in layer 2/3 of rat primary visual cortex. J Neurosci 17:7926-7940.

Varela JA, Song S, T urrigiano GG, Nelson SB (1999) Differential depression at excitatory and inhibitory synapses in visual cortex. J Neurosci 19:4293-4304.

Volgushev M, Chistiakova M, Singer W (1998) Modification of discharge patterns of neocortical neurons by induced oscillations of the membrane potential. Neuroscience 83:15-25.

Zucker RS (1989) Short-term synaptic plasticity. Annu Rev Neurosci 12: 13-31. 